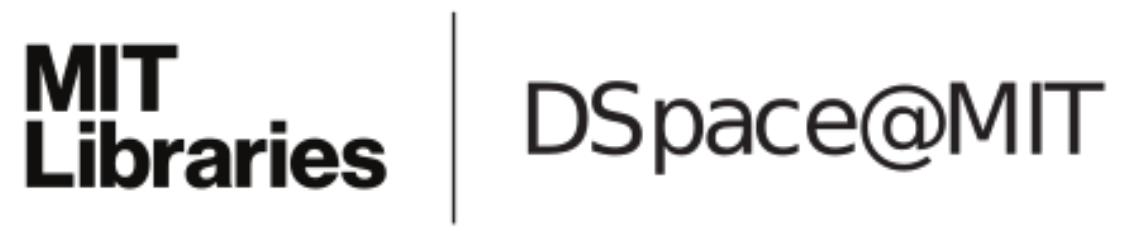

\author{
MIT Open Access Articles
}

Morphology-Dependent Luminescence in Complex Liquid Colloids

The MIT Faculty has made this article openly available. Please share how this access benefits you. Your story matters.

Citation: Lin, Che-Jen et al. "Morphology-Dependent Luminescence in Complex Liquid Colloids." Journal of the American Chemical Society 141, 9 (February 2019): 3802-3806 @ 2019 American Chemical Society

As Published: http://dx.doi.org/10.1021/jacs.8b13215

Publisher: American Chemical Society (ACS)

Persistent URL: https://hdl.handle.net/1721.1/128145

Version: Author's final manuscript: final author's manuscript post peer review, without publisher's formatting or copy editing

Terms of Use: Article is made available in accordance with the publisher's policy and may be subject to US copyright law. Please refer to the publisher's site for terms of use. 


\title{
Morphology-Dependent Luminescence in Complex Liquid Colloids
}

\author{
Che-Jen Lin, Lukas Zeininger, Suchol Savagatrup, and Timothy M. Swager* \\ Department of Chemistry and Institute for Soldier Nanotechnologies, Massachusetts Institute of Technology, 77 Massachusetts Avenue, Cambridge \\ Massachusetts 02139, United States
}

Supporting Information Placeholder

\begin{abstract}
Complex liquid colloids hold great promise as transducers in sensing applications as a result of their tunable morphology and intrinsic optical properties. Herein, we introduce meta-amino substituted green fluorescence protein chromophore (GFPc) surfactants that localize at the organic-water interface of complex multiphase liquid colloids. The meta-amino GFPc exhibits hydrogen-bonding (HB) mediated fluorescence quenching, and are nearly non-emissive in the presence of protic solvents. We demonstrate morphology-dependent fluorescence of complex liquid colloids and investigate the interplay between GFPc surfactants and other simple surfactants. This environmentally responsive surfactant allows us to observe morphological changes of complex emulsions in randomized orientations. We demonstrate utility with an enzyme activity based fluorescence "turn-ON" scheme. The latter employs an oligopeptide-linked GFPc that functions as both a surfactant and trypsin target. The cleavage of hydrophilic peptide results in a morphology change and ultimately a fluorescence turn-on. Fluorescent complex colloids represent a new approach for biosensing in liquid environments.
\end{abstract}

Green fluorescence protein (GFP) has been widely applied in bioimaging and biosensors. ${ }^{1}$ The wild-type GFP generates intense fluorescence $\left(\Phi_{f} \sim 0.8\right)$, but the isolated chromophore (GFPC) is nonemissive in organic solvents $\left(\Phi_{f}<10^{-3}\right)$. ${ }^{1 a}$ This behavior arises because the $\beta$-barrel structure of wild-type GFP constrains conformational flexibility. To increase fluorescence, synthetic GFP chromophores (GFPC) have been produced with constraining covalent structures, ${ }^{2}$ or non-covalent hydrogen bonding. ${ }^{3}$ In addition to structural confinement, electronic effects can also be used to enhance the fluorescence. ${ }^{4}$ To this end, Yang and co-workers reported fluorescence enhancement by installing an amino group at meta-position on phenyl ring (meta-amino effect). ${ }^{5}$ More importantly, the meta-amino substituted GFPC exhibits hydrogen-bonding (HB) mediated fluorescence quenching that is not observed in other synthetic GFPC constructions. Accordingly metadimethylamino GFPC (D1A1) displays strong fluorescence $\left(\Phi_{f}=0.46\right)$ in hexane, but weak fluorescence in methanol or water $\left(\Phi_{f} \sim 10^{-4}\right) \cdot{ }^{6}$ The remarkable fluorescence difference between aprotic and protic solvents has been applied to the imaging of lipophilic cell membranes. ${ }^{7}$ A key advantage of the HB mediated quenching is that this method achieves high contrast without removing excess dyes from the aqueous solution.

Sensors that optimally function in aqueous solutions are of great interest to the food industry, for detecting water pollution, and for medical diagnostics. ${ }^{8}$ Many methods make use of solid-state sensing materials including metal nanoparticles, silica nanoparticles, polymers, and carbon-based nanomaterials. 9 Recently, our group has focused on developing multiphase liquid droplet-based sensing platforms for biosensing. ${ }^{10}$ These complex colloids consist of organic (herein a hydrocarbon, $\mathrm{H})$ and fluorocarbon (F) oils, dispersed in an aqueous phase (W). Dynamic fluid particles have advantages over solidstate materials in biosensing wherein the biomolecular recognition elements at the surfactant-water interface experience an environment that more closely resembles those found in nature. We have made use of morphology changes in complex colloids that can be triggered to change between hydrocarbon-in-fluorocarbon-in-water double emulsions (H/F/W), Janus emulsions, and inverted double emulsions (fluorocarbon-in-hydrocarbon-in-water $\mathrm{F} / \mathrm{H} / \mathrm{W}$ ) (Figure S1). ${ }^{11}$ Analyte-responsive surfactants can be used to induce these morphological changes, ${ }^{12}$ to produce observable responses through optical scattering ${ }^{13}$ and directional emission. ${ }^{14}$ However, in these previous studies the observables require gravity aligned colloids, which can limit the use in turbulent media. In order to improve the simplicity of the optical read-out, we have targeted the complex fluid emulsions that give changes in fluorescence intensity in response to morphology changes.

Herein, we detail a meta-amino substituted amphiphilic GFPc (D8AEG) containing octyl chains and triethylene glycol (Error! Reference source not found.), which is organic soluble but localizes at $\mathrm{H} / \mathrm{W}$ interfaces. The 
fluorescence intensity is dependent on $\mathrm{H} / \mathrm{W}$ interfacial surface area where HB-induced quenching occurs. Specifically, an increasing $\mathrm{H} / \mathrm{W}$ interfacial area associated with the phase progression from a $\mathrm{H} / \mathrm{F} / \mathrm{W}$ to a $\mathrm{F} / \mathrm{H} / \mathrm{W}$ state results in decreased fluorescence. This GFP-scheme thereby provides a fluorescent read-out of a morphology change in randomly orientated emulsions with active mixing. To enable this process for biosensing, a peptide-linked GFPc (D8AP) for detecting trypsin activity has also been produced. Trypsin is a pancreatic digestive enzyme and cleaves specific peptide bonds in protein. For healthy individuals, trypsin levels are balanced by pancreatic secretory trypsin inhibitor (PSTI), whereas, an increasing trypsin level can rise to $84.4 \mu \mathrm{g} / \mathrm{mL}$ in a patient's urine and indicate pancreatitis or pancreatic cancers. ${ }^{15}$ To sense this protease, we use the following sequence, [H]-Val-Gly-LysGlu-Ala- $\left[\mathrm{NH}_{2}\right]$, in which trypsin will specifically cleave at the C-terminal of lysine. ${ }^{16}$ The peptide sequence also contains hydrophobic Val group connecting the hydrophobic GFPc to hydrophilic zwitterionic Lys-Glu-Ala residues. As a result, D8AP functions as a surfactant in $\mathrm{F} / \mathrm{H} / \mathrm{W}$ double emulsions placing the GFPc in a HB quenching environment. Trypsin treatment removes the hydrophilic peptide and the fluorocarbon surfactant in the aqueous phase affects a transition to an emissive $\mathrm{H} / \mathrm{F} / \mathrm{W}$ double emulsion (fluorescence $\mathrm{ON}$ ). In this way GFPc-containing complex colloids can enable label-free biosensing.

\section{Chart 1. Structures of GFPc}
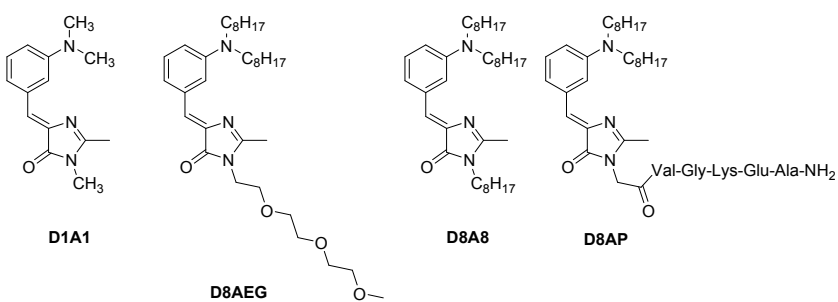

D8AEG exhibits intense emission in hexane $\left(\Phi_{\mathrm{em}}=13.5 \%\right)$ and nearly non-emissive in methanol $\left(\Phi_{\mathrm{em}}<0.1 \%\right)$. The HBinduced quenching is highly efficient and the addition of 0.024 equivalent methanol to a solution in heptane results in a 17 fold reduction in fluorescence intensity and spectral redshifts due to increasing polarity (Error! Reference source not found.). We use anthracene as an internal reference because it lacks the same environmental sensitivity and has an emission spectrum that is well separated from that of D8AEG. ${ }^{17}$ To examine the substituent effects, we conducted comparative photo-physical studies on D8A8, which shows similar fluorescence quantum yields in aprotic solvents (Table S1), and its emission is also quenched in methanol. Hence, the ethylene glycol group has little influence on luminescence properties. Complete photo-physical characterizations (Figure S2-3 and Table S1) and TD-DFT calculations (Figure S4 and Table S1) of D8AEG and D8A8 were provided in Supporting Information.

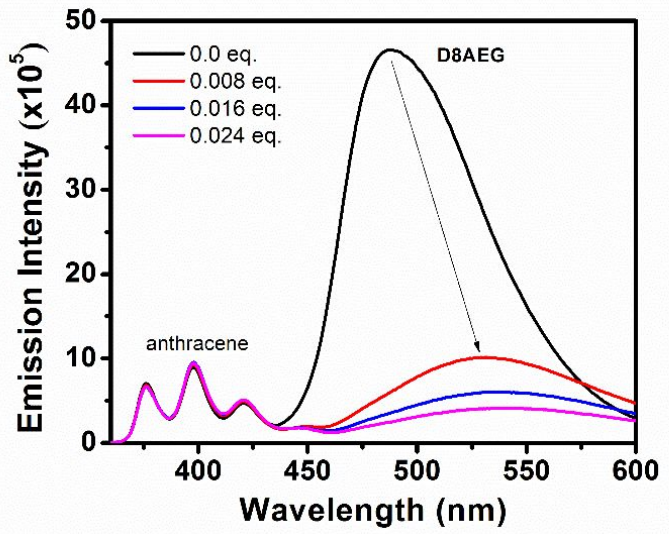

Figure 1. Emission spectra of D8AEG $\left(1.0 \times 10^{-5} \mathrm{M}\right)$ and anthracene $\left(2.0 \times 10^{-6} \mathrm{M}\right)$ in heptane with methanol addition.

To create complex liquid droplets, we emulsified a heptane solution containing D8AEG $\left(1.0 \times 10^{-5} \mathrm{M}\right)$ and fluorocarbon oil (FC-770) at a temperature above their upper consolute temperature in a water-surfactant solution. ${ }^{12}$ The $\mathrm{H} / \mathrm{F} / \mathrm{W}$, $\mathrm{F} / \mathrm{H} / \mathrm{W}$, and Janus droplets were generated in $0.1 \%$ Zonyl (Sigma Aldrich), 0.1\% sodium dodecyl sulfate (SDS), and $0.05 \%$ Zonyl/SDS (1:1, v/v) surfactant solutions, respectively. The polydisperse droplets created by temperature-induced phase separation method range from 10-200 $\mu \mathrm{m}$ (Figure S5) and Figure 2a shows the photograph of luminescent droplets under $365 \mathrm{~nm}$ irradiation. Both $\mathrm{H} / \mathrm{F} / \mathrm{W}$ and Janus morphology show intense fluorescence, whereas $\mathrm{F} / \mathrm{H} / \mathrm{W}$ double emulsion displays weaker emission. From the confocal images in Figure $2 b$, we clearly observe that the fluorescence originates from the inner heptane phase in the $\mathrm{H} / \mathrm{F} / \mathrm{W}$ morphology, and from the outer heptane layer in $\mathrm{F} / \mathrm{H} / \mathrm{W}$ double emulsion. This observation is consistent with the expected behavior wherein increasing $\mathrm{H} / \mathrm{W}$ interfacial area produces more fluorescence quenching.

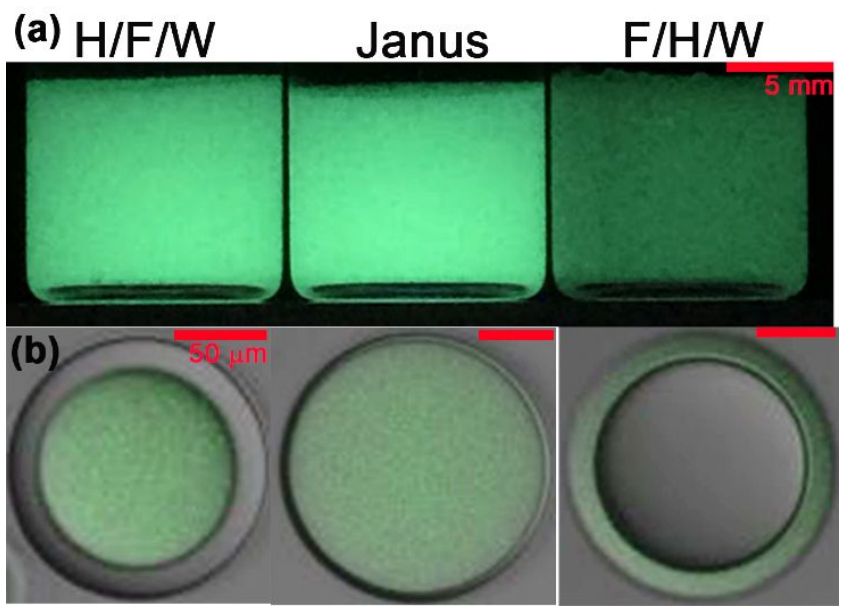

Figure 2. (a) Droplets in 2-mL vials under $365 \mathrm{~nm}$ irradiation (scale bar: $5 \mathrm{~mm}$ ) and (b) confocal images of D8AEG in H/F/W (left), aligned Janus (middle), and $\mathrm{F} / \mathrm{H} / \mathrm{W}$ (right) morphology. Scale bar: $50 \mu \mathrm{m}$.

A quantitative fluorescent analysis of a droplet morphology change is realized through the anthracene internal reference to compare fluorescence intensity between morphologies. ${ }^{11}$,

18 This ratiometric scheme (i.e. $I_{\mathrm{D} 8 \mathrm{AEG}} / I_{\mathrm{An}}$ ) corrects for any 
optical effects associated with the different morphologies at different fractions of SDS $\left(f_{\mathrm{SDS}}\right)$ in the water (Figure 3$)$. The system behaves as anticipated with a decrease of $I_{\mathrm{D} 8 \mathrm{AEG}} / I_{\mathrm{An}}$ with increasing $f_{\text {SDS. It }}$ is also noteworthy that fluorescence of colloids with the purely hydrophobic D8A8 is nearly independent on the surfactant compositions. The fluorescence of D8AEG decreases by $15 \%$ at $f_{\mathrm{SDS}}=0.2$, and the decline has a smaller linearly decreasing slope from $f_{\mathrm{SDS}}$ $=0.2-0.8$. At $f_{\mathrm{SDS}}>0.8$ the fluorescence decreases more steeply from $82 \%$ to $73 \%$ wherein SDS is the sole surfactant. The side-view images in Figure 4 reveal the morphological variation, and we measured the $\mathrm{H} / \mathrm{W}$ interfacial fractional areas via image processing using the side-view micrographs of the droplets. The fraction of exposed $\mathrm{H} / \mathrm{W}$ area is provided in Figure 3. The exposed $\mathrm{H} / \mathrm{W}$ surface area increases $30 \%$ and $35 \%$ for $f_{\mathrm{SDS}}=0 \rightarrow 0.2$ and $0.8 \rightarrow 1.0$, respectively. The central region corresponds to Janus morphology with a slow increase of $\mathrm{H} / \mathrm{W}$ interfacial area and decrease of fluorescence. It should be noted that the relative emission of Janus morphology is weaker than that of $\mathrm{H} / \mathrm{F} / \mathrm{W}$ double emulsion, but Janus droplets displays the brightest luminescence images in Figure 2a. This difference is the result of lower optical scattering by the Janus droplets. ${ }^{11,18}$ Moreover, in the case of D8A8, the HB mediated quenching is negligible even in pure SDS solution. This non-quenching behavior indicates that the SDS preferably occupies the interface and this hydrophobic dye has minimal interaction with the water.

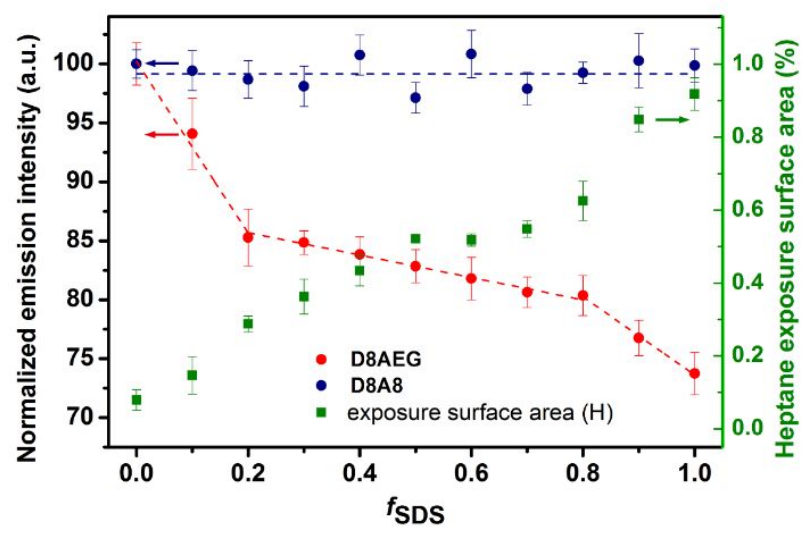

Figure 3. The normalized relative fluorescence intensities (relative to anthracene internal standard) of colloids containing D8AEG (red) and D8A8 (blue) in surfactant solutions having varing ratios of Zonyl and SDS. The heptane exposured surface area to water is shown as right y-axis (green).

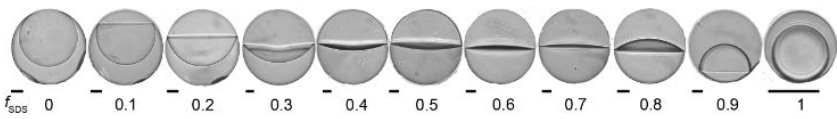

Figure 4. Side-view microscope images of droplets containing $2 \times$ $10^{-4} \mathrm{M}$ D8AEG in heptane-FC770 solutions of $0.1 \%$ Zonyl and $0.1 \%$ SDS in varying ratio as plotted in Figure 4. Scale bars: 10 $\mu \mathrm{m}$.
To understand the interplay between SDS and GFPc, we prepared droplets containing D8AEG and anthracene (both $1.0 \times 10^{-5} \mathrm{M}$ ) in a $\mathrm{F} / \mathrm{H} / \mathrm{W}$ morphology at different SDS concentrations $(0.001-0.15 \%$, wt $\%)$. The normalized droplet emission vs. SDS concentration are shown in Figure $5 \mathrm{a}$. The fluorescence intensity gradually decreases with lower SDS concentrations indicating more $\mathrm{H} / \mathrm{W}$ interfacial accessibility for the D8AEG molecules. To examine the role of surfactant structure we studied the emission intensity of droplets stabilized by sodium dodecylbenzyl sulfate (SDBS), Tween 20, and Triton X-100 (Figure 5b, Error! Reference source not found.). In SDBS solution, the fluorescence intensity drops when concentrations are below $0.01 \%$, whereas fluorescence intensity is independent of Tween 20 and triton X-100 (0.001-0.10\%). SDBS with phenyl ring has larger steric hindrance compared to SDS, which lowers the interfacial accessibility for D8AEG at high SDBS concentrations. Similar steric effects may be responsible for the trend with non-ionic Tween 20 and Triton X-100. The PEG chains of Tween 20 and Triton X-100 have steric congestion on hydrophilic side and form steric shell to stabilize droplets. ${ }^{19}$ The steric effects leads to the independence of fluorescence on the concentration of the non-ionic surfactant.
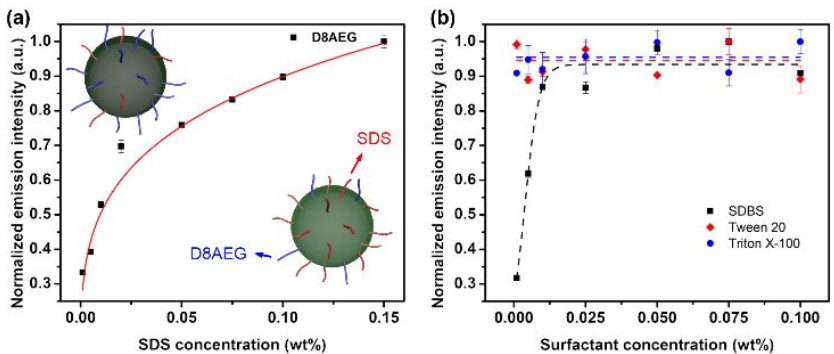

Figure 5. Relative emission intensity of D8AEG to anthracene in (a) SDS and (b) SDBS, Tween 20 and Triton X-100 solutions.

\section{Chart 2. Structures of surfactants}

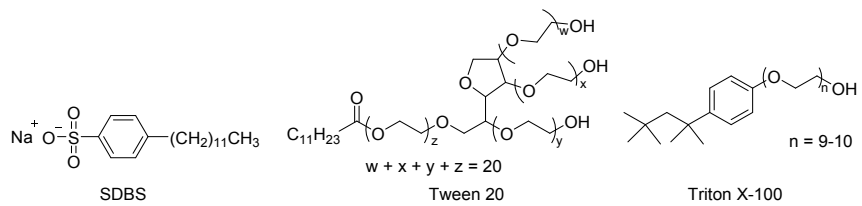

The luminescence-morphology relationships described can be used to create a fluorescence ON-OFF detection scheme for enzymatic activity. We designed a surfactant-GFPc (D8AP) with an oligopeptide chain, Val-Gly-Lys-Glu-Ala$\left[\mathrm{NH}_{2}\right]$ and the synthesis is shown in Scheme 1. D8ACOOH was synthesized by modified protocol ${ }^{7}$ wherein D8AP was synthesized by amidiation of the D8ACOOH to the peptide, [H]-Val-Gly-Lys-Glu-Ala-[ $\left.\mathrm{NH}_{2}\right]$. The zwitterionic LysGlu-Ala endows D8AP with greater surfactant effectiveness relative to D8AEG. The D8AP containing colloids were firstly prepared by emulsification of oils in $1 \mathrm{~mL} 0.01 \%$ Tween-20 PBS buffer. These droplets remained in the $\mathrm{F} / \mathrm{H} / \mathrm{W}$ morphology after adding $1 \mathrm{~mL} 1 \%$ Zonyl, and the fact that the added fluorocarbon surfactant doesn't effect a morphology change indicates that D8AP is a powerful surfactant. 


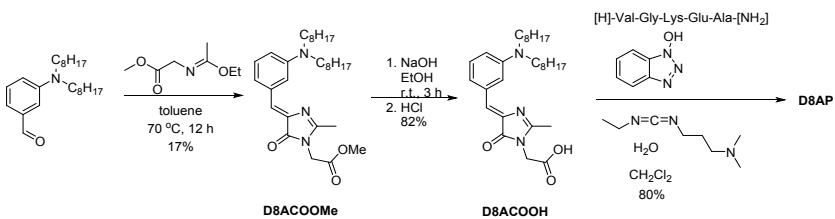

Scheme 1. Synthetic route of D8AP.

Trypsin exclusively cleaves at the C-terminal of lysine ${ }^{16}$ and converts D8AP to D8AP'. This treatment can lead to morphology changes with a fluorescence turn-on (Figure 6a). The confocal images of D8AP and D8AP' in droplets captured under the same conditions (exposure time and laser pinhole) are shown in Figure $6 \mathrm{~b}$ and $\mathrm{c}$, respectively. Without trypsin treatment, the D8AP colloids remain in $\mathrm{F} / \mathrm{H} / \mathrm{W}$ morphology with weak emission from outer layer (Figure 6b). Trypsin conversion to D8AP' changes the morphology to $\mathrm{a} / \mathrm{F} / \mathrm{W}$ double emulsion accompanied by a fluorescence turn-on (Figure 6c). The evolution of morphology is shown in Figure S7. Morphology changes from $\mathrm{F} / \mathrm{H} / \mathrm{W}$ to Janus after $1 \mathrm{~h}$ and transforms to a H/F/W morphology after $8 \mathrm{~h}$. The shorter reaction time from $\mathrm{F} / \mathrm{H} / \mathrm{W}$ to Janus is consistent with the smaller $\Delta f_{\text {sds }}(1.0 \rightarrow 0.8)$ with the same morphology change in Figure 3. Monitoring the window between double emulsion and Janus allows us to shorten the detection time. In a concentration of $0.6 \mathrm{mg} / \mathrm{mL}$ D8AP colloids, this morphology change is observed for a trypsin concentration of $50 \mu \mathrm{g} / \mathrm{mL}$ and presently this system stands as a simple proof of concept demonstration. However, we envisage that similar morphology-dependent luminescent complex colloids can result in biosensors that are facilitated by simple fabrication, easy read-out schemes, and natural stability in aqueous systems.

(a)
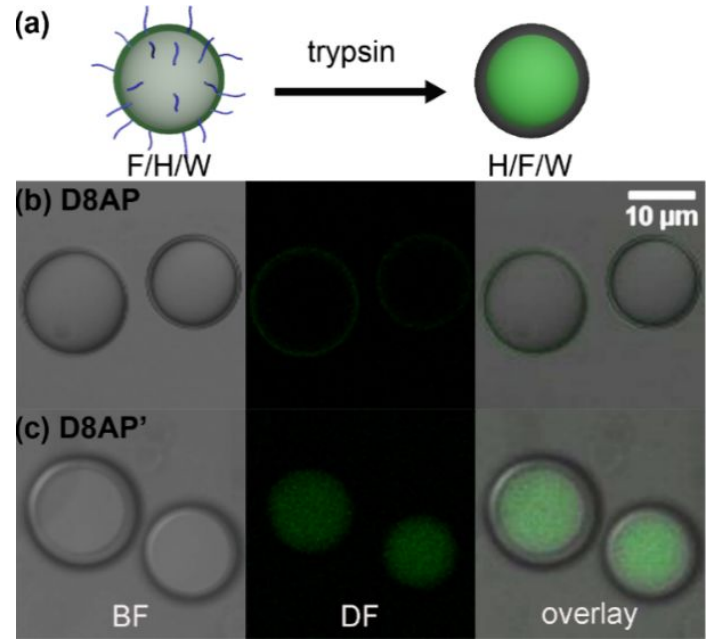

Figure 6. (a) Schematic drawing of D8AP (blue) droplets with trypsin. Confocal images (bright field, dark field and overlay) of D8AP after incubation (b) without trypsin and (c) with trypsin at $37{ }^{\circ} \mathrm{C}$ for $12 \mathrm{~h}$.

To summarize, we reported GFPc-dyed complex colloids that exhibit strong correlation between their fluorescence intensity and morphology. The fluorescence is quenched by hydrogen-bonding in $\mathrm{F} / \mathrm{H} / \mathrm{W}$ emulsions, but increases upon transformation to a $\mathrm{H} / \mathrm{F} / \mathrm{W}$ and Janus emulsion giving a turnon response. We investigated the influence of surfactants on the HB-induced quenching at the interface. We established a fluorescent complex colloid to detect trypsin activity based on fluorescence turn-on and morphological change. The simple to fabricate complex colloids and facile optical readout provides a new approach for biological and chemical sensing. A diversity biosensors based on fluorescent complex liquid colloids are envisioned for the future.

\section{ASSOCIATED CONTENT}

\section{Supporting Information}

The Supporting Information is available free of charge on the ACS Publications website at doi.

The schematic side-view of morphologies of colloids, synthesis, photo-physical characterization and TD-DFT calculations of D8AEG and D8A8, confocal images of D8AEG in heptane/FC770 colloids, confocal images of D8AP incubated with trypsin, normalized emission of D8AEG and anthracene in $\mathrm{H} / \mathrm{F} / \mathrm{W}$ morphologies of heptane/FC770 colloids, and experimental procedures, details of the characterization.

\section{AUTHOR INFORMATION}

\section{Corresponding Author}

tswager@mit.edu

ORCID

Che-Jen Lin: 0000-0001-9287-6795

Timothy M. Swager: 0000-0002-3577-0510

\section{Notes}

The authors declare no competing financial interests.

\section{ACKNOWLEDGMENT}

This work was supported by National Institutes of Health of General Medical Sciences (Grant No. GM095843). C. L. acknowledges support from the Minister of Science and Technology, Taiwan. (MOST, 106-2917-I-564-058) L.Z. acknowledges support from the German Research Foundation (DFG, Grant No. ZE1121/1-1). S.S. was supported by an F32 Ruth L. Kirschstein National Research Service Award.

\section{REFERENCES}

1. (a) Tsien, R. Y., The Green Fluorescent Protein. Annu. Rev. Biochem 1998, 67, 509-544; (b) Zhang, J.; Campbell, R. E.; Ting, A. Y.; Tsien, R. Y., Creating new fluorescent probes for cell biology. Nat. Rev. Mol. Cell Biol. 2002, 3, 906-918; (c) Zimmer, M., Green Fluorescent Protein (GFP): Applications, Structure, and Related Photophysical Behavior. Chem. Rev. 2002, 102, 759-782; (d) Chudakov, D. M.; Lukyanov, S.; Lukyanov, K. A., Fluorescent proteins as a toolkit for in vivo imaging. Trends Biotechnol. 2005, 23, 605-613; (e) Day, R. N.; Davidson, M. W., The fluorescent protein palette: tools for cellular imaging. Chem. Soc. Rev. 2009, 38, 2887-2921; (f) Walker, C. L.; Lukyanov, K. A.; Yampolsky, I. V.; Mishin, A. S.; Bommarius, A. S.; Duraj-Thatte, A. M.; Azizi, B.; Tolbert, L. M.; Solntsev, K. M., Fluorescence imaging using synthetic GFP chromophores. Curr. Opin. Chem. Biol. 2015, 27, 64-74; (g) Tolbert, L. M.; Baldridge, A.; Kowalik, J.; Solntsev, K. M., Collapse and Recovery of 
Green Fluorescent Protein Chromophore Emission through Topological Effects. Acc. Chem. Res. 2012, 45, 171-181.

2. (a) Wu, L.; Burgess, K., Syntheses of Highly Fluorescent GFPChromophore Analogues. J. Am. Chem. Soc. 2008, 130, 4089-4096; (b) Baranov, M. S.; Solntsev, K. M.; Baleeva, N. S.; Mishin, A. S.; Lukyanov, S. A.; Lukyanov, K. A.; Yampolsky, I. V., Red-Shifted Fluorescent Aminated Derivatives of a Conformationally Locked GFP Chromophore. Chem. Eur. J. 2014, 20, 13234-13241.

3. (a) Chen, K.-Y.; Cheng, Y.-M.; Lai, C.-H.; Hsu, C.-C.; Ho, M.L.; Lee, G.-H.; Chou, P.-T., Ortho Green Fluorescence Protein Synthetic Chromophore; Excited-State Intramolecular Proton Transfer via a SevenMembered-Ring Hydrogen-Bonding System. J. Am. Chem. Soc. 2007, 129, 4534-4535; (b) Chuang, W.-T.; Hsieh, C.-C.; Lai, C.-H.; Lai, C.-H.; Shih, C.-W.; Chen, K.-Y.; Hung, W.-Y.; Hsu, Y.-H.; Chou, P.-T., Excited-State Intramolecular Proton Transfer Molecules Bearing o-Hydroxy Analogues of Green Fluorescent Protein Chromophore. J. Org. Chem. 2011, 76, 81898202; (c) Hsu, Y.-H.; Chen, Y.-A.; Tseng, H.-W.; Zhang, Z.; Shen, J.-Y.; Chuang, W.-T.; Lin, T.-C.; Lee, C.-S.; Hung, W.-Y.; Hong, B.-C.; Liu, S.H.; Chou, P.-T., Locked ortho- and para-Core Chromophores of Green Fluorescent Protein; Dramatic Emission Enhancement via Structural Constraint. J. Am. Chem. Soc. 2014, 136, 11805-11812; (d) Deng, H.; Zhu, X., Emission enhancement and application of synthetic green fluorescent protein chromophore analogs. Mater. Chem. Front. 2017, 1, 619-629.

4. Gutiérrez, S.; Martínez-López, D.; Morón, M.; Sucunza, D.; Sampedro, D.; Domingo, A.; Salgado, A.; Vaquero, J. J., Highly Fluorescent Green Fluorescent Protein Chromophore Analogues Made by Decorating the Imidazolone Ring. Chem. Eur. J. 2015, 21, 18758-18763.

5. (a) Yang, J.-S.; Huang, G.-J.; Liu, Y.-H.; Peng, S.-M., Photoisomerization of the green fluorescence protein chromophore and the meta- and para-amino analogues. Chem. Commun. 2008, 1344-1346; (b) Tsai, M.-S.; Ou, C.-L.; Tsai, C.-J.; Huang, Y.-C.; Cheng, Y.-C.; Sun, S.-S.; Yang, J.-S., Fluorescence Enhancement of Unconstrained GFP Chromophore Analogues Based on the Push-Pull Substituent Effect. $J$. Org. Chem. 2017, 82, 8031-8039.

6. (a) Huang, G.-J.; Ho, J.-H.; Prabhakar, C.; Liu, Y.-H.; Peng, S.M.; Yang, J.-S., Site-Selective Hydrogen-Bonding-Induced Fluorescence Quenching of Highly Solvatofluorochromic GFP-like Chromophores. Org. Lett. 2012, 14, 5034-5037; (b) Huang, G.-J.; Cheng, C.-W.; Hsu, H.-Y.; Prabhakar, C.; Lee, Y.-P.; Diau, E. W.-G.; Yang, J.-S., Effects of Hydrogen Bonding on Internal Conversion of GFP-like Chromophores. I. The paraAmino Systems. J. Phys. Chem. B 2013, 117, 2695-2704.

7. Tou, S.-L.; Huang, G.-J.; Chen, P.-C.; Chang, H.-T.; Tsai, J.-Y.; Yang, J.-S., Aggregation-induced emission of GFP-like chromophores via exclusion of solvent-solute hydrogen bonding. Chem. Commun. 2014, 50, 620-622.

8. (a) Turner, A. P. F., Biosensors: sense and sensibility. Chem. Soc. Rev. 2013, 42, 3184-3196; (b) Li, Z.; Askim, J. R.; Suslick, K. S., The
Optoelectronic Nose: Colorimetric and Fluorometric Sensor Arrays. Chem. Rev. 2019, 119, 231-292.

9. (a) Chen, L.; Hwang, E.; Zhang, J., Fluorescent Nanobiosensors for Sensing Glucose. Sensors 2018, 18, 1440; (b) Schroeder, V.; Savagatrup, S.; He, M.; Lin, S.; Swager, T. M., Carbon Nanotube Chemical Sensors. Chem. Rev. 2019, 119, 599-663 ; (c) Holzinger, M.; Le Goff, A.; Cosnier, S., Nanomaterials for biosensing applications: a review. Front. Chem. 2014, 2, 63; (d) Kassal, P.; Steinberg, M. D.; Steinberg, I. M., Wireless chemical sensors and biosensors: A review. Sens. Actuators, B Chem. 2018, 266, 228-245.

10. (a) Tadros, T. F., Emulsion Science and Technology: A General Introduction. In Emulsion Science and Technology, Wiley-VCH Verlag GmbH \& Co. KGaA: 2009; pp 1-56; (b) Jiao, J.; Burgess, D. J., Multiple Emulsion Stability: Pressure Balance and Interfacial Film Strength. In Multiple Emulsions, John Wiley \& Sons, Inc.: 2007; pp 1-27.

11. Zarzar, L. D.; Kalow, J. A.; He, X.; Walish, J. J.; Swager, T. M., Optical visualization and quantification of enzyme activity using dynamic droplet lenses. Proc. Natl. Acad. Sci. 2017, 114, 3821-3825.

12. Zarzar, L. D.; Sresht, V.; Sletten, E. M.; Kalow, J. A.; Blankschtein, D.; Swager, T. M., Dynamically reconfigurable complex emulsions via tunable interfacial tensions. Nature 2015, 518, 520-524.

13. Zhang, Q.; Savagatrup, S.; Kaplonek, P.; Seeberger, P. H.; Swager, T. M., Janus Emulsions for the Detection of Bacteria. ACS Cent. Sci. 2017, 3, 309-313.

14. Zeininger, L. N., S.; Harvey, K. S.; Savagatrup, S.; Herbert, M. B.; Yoshinaga, K.; Capobianco, J. A.; Kolle, M.; Swager, T. M., Rapid Detection of Salmonella Enterica via Directional Emission from Dynamic Liquid Colloids. Submitted.

15. See, W. A.; Smith, J. L., Urinary Levels of Activated Trypsin in Whole-Organ Pancreas Transplant Patients with Duodenocystostomies. Transplantation 1991, 52, 630-633.

16. Olsen, J. V.; Ong, S.-E.; Mann, M., Trypsin Cleaves Exclusively C-terminal to Arginine and Lysine Residues. Mol. Cell. Proteomics 2004, 3, 608-614.

17. Brouwer, A. M., Standards for photoluminescence quantum yield measurements in solution (IUPAC Technical Report). Pure Appl. Chem. 2011, 83, 2213-2228.

18. Nagelberg, S.; Zarzar, L. D.; Nicolas, N.; Subramanian, K.; Kalow, J. A.; Sresht, V.; Blankschtein, D.; Barbastathis, G.; Kreysing, M.; Swager, T. M.; Kolle, M., Reconfigurable and responsive droplet-based compound micro-lenses. Nat. Commun. 2017, 8, 14673-14681.

19. Rosen, M. J.; Kunjappu, J. T., Surfactants and Interfacial Phenomena (4th Edition). In Surfactants and Interfacial Phenomena, John Wiley \& Sons: 2012. 


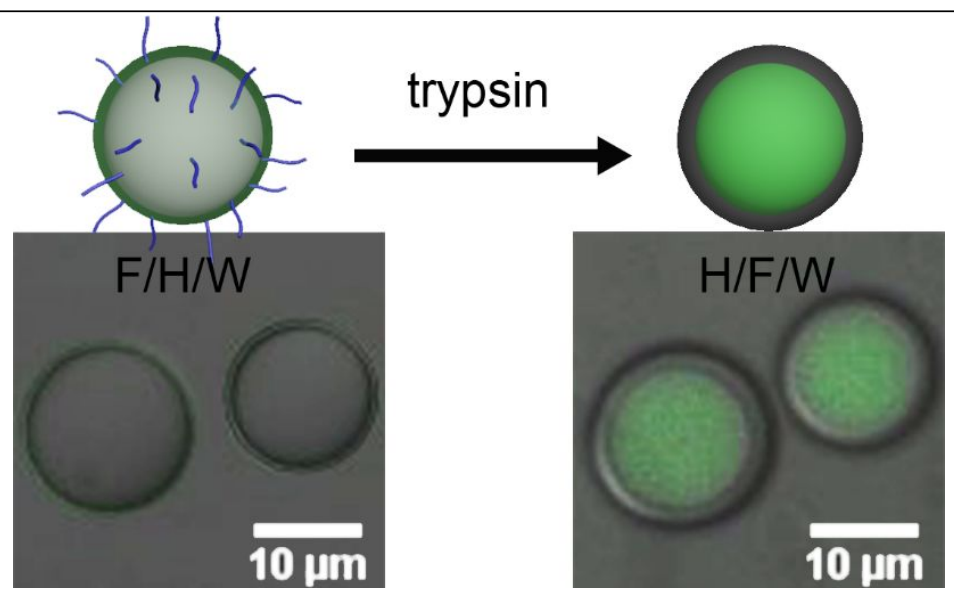

